\title{
RESEARCH
}

Open Access

\section{IRE1a inhibition attenuates neuronal pyroptosis via miR-125/NLRP1 pathway in a neonatal hypoxic-ischemic encephalopathy rat model}

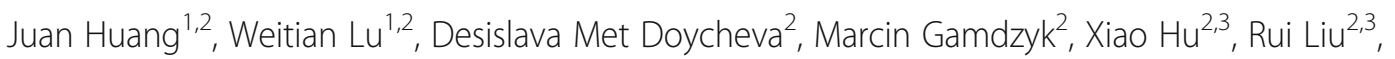
John H. Zhang ${ }^{2,4,5}$ and Jiping Tang ${ }^{2 *}$

\begin{abstract}
Background: Inhibition of inositol-requiring enzyme-1 alpha (IRE1a), one of the sensor signaling proteins associated with endoplasmic reticulum (ER) stress, has been shown to alleviate brain injury and improve neurological behavior in a neonatal hypoxic-ischemic encephalopathy (HIE) rat model. However, there is no information about the role of IRE1a inhibitor as well as its molecular mechanisms in preventing neuronal pyroptosis induced by NLRP1 (NOD-, LRR- and pyrin domain-containing 1) inflammasome. In the present study, we hypothesized that IRE1 a can degrade microRNA-125-b-2-3p (miR-125-b-2-3p) and activate NLRP1/caspased-1 pathway, and subsequently promote neuronal pyroptosis in HIE rat model.

Methods: Ten-day old unsexed rat pups were subjected to hypoxia-ischemia (HI) injury, and the inhibitor of IRE1a, STF083010, was administered intranasally at $1 \mathrm{~h}$ after HI induction. AntimiR-125 or NLRP1 activation CRISPR was administered by intracerebroventricular (i.c.v) injection at $24 \mathrm{~h}$ before $\mathrm{HI}$ induction. Immunofluorescence staining, western blot analysis, reverse transcription quantitative real-time polymerase chain reaction (RT-qPCR), brain infarct volume measurement, neurological function tests, and Fluoro-Jade C staining were performed.

Results: Endogenous phosphorylated IRE1a (p-IRE1a), NLRP1, cleaved caspase-1, interleukin-1 $\beta$ (IL-1 $\beta$ ), and interleukin-18 (IL-18) were increased and miR-125-b-2-3p was decreased in HIE rat model. STF083010 administration significantly upregulated the expression of miR-125-b-2-3p, reduced the infarct volume, improved neurobehavioral outcomes and downregulated the protein expression of NLRP1, cleaved caspase-1, IL-1 $\beta$ and IL-18. The protective effects of STF083010 were reversed by antimiR-125 or NLRP1 activation CRISPR.
\end{abstract}

Conclusions: IRE1a inhibitor, STF083010, reduced neuronal pyroptosis at least in part via miR-125/NLRP1/caspase-1 signaling pathway after $\mathrm{HI}$.

Keywords: Hypoxic-ischemic encephalopathy, IRE1a, miR-125, NLPR1, Inflammasome, Pyroptosis

\footnotetext{
* Correspondence: jtang@llu.edu

${ }^{2}$ Department of Physiology and Pharmacology, Loma Linda University, Risley

Hall, 11041 Campus St, Loma Linda, CA 92350, USA

Full list of author information is available at the end of the article
}

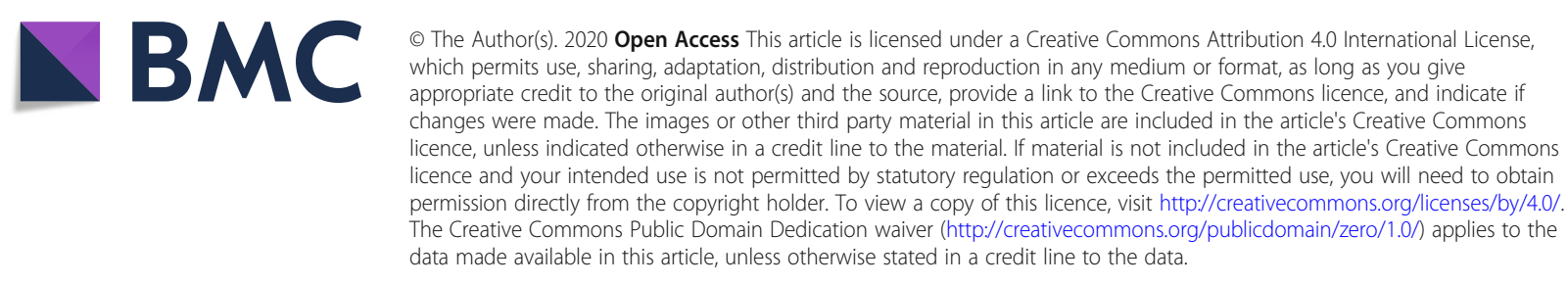




\section{Background}

Neonatal hypoxic ischemic encephalopathy (HIE) is a devastating disease that causes perinatal brain injury and leads to prolonged neurodevelopmental consequences in infants including cerebral palsy, cognitive deficits, mental retardation, seizures, epilepsy, and other neurological disabilities [1-3]. Although there has been tremendous progress in understanding HIE pathologies, there is still a need to explore its pathophysiology and treatment modalities [3].

Growing evidence reveal that endoplasmic reticulum (ER) stress is involved in the pathogenesis of HIE [4-7]. ER stress is the condition where ER homeostasis is disturbed and the unfolded or misfolded proteins accumulate in the ER lumen, which can be caused by many physiological or pathological factors, such as hypoxia, ischemia, or changes in intracellular $\mathrm{pH}[5,8-10]$. Inositol-requiring enzyme 1 alpha (IRE1 $\alpha$ ), an ER transmembrane kinase-endoribonuclease (RNase), is a stress sensor receptor, which is activated by the accumulation of unfolded or misfolded proteins [11, 12]. It has been reported that sustained IRE1 $\alpha$ activation causes rapid decay of some microRNAs (miRNAs), such as miR-17 and miR-125 [13].

miRNAs are a class of noncoding short singlestranded RNAs ( $\sim 22 \mathrm{nt}$ in length) that play a role in downregulating gene expression at the post transcriptional level via binding to complementary nucleotide sequences of the target mRNA [14-18]. Our previous research showed that IRE1 $\alpha$ inhibition alleviated brain injury and restrained the activation of TXNIP/NLRP3 inflammasome via upregulating miR-17 expression level in neonatal HIE rat model [5]. However, whether IRE1 inhibition may be protective via regulation of miR-125 expression levels has not been studied.

Neuronal pyroptosis, a form of programmed neuronal cell death, initiated by caspase-1, is one of the important causes of neurological damage [19]. The nucleotidebinding oligomerization domain (NOD)-like receptor (NLR) pyrin domain-containing (NLRP) inflammasomes have recently been identified and shown to contribute to cell pyroptosis [20, 21]. Inflammasomes are the multiprotein complexes composed of a cytosolic patternrecognition receptor, the enzyme caspase 1 and an adaptor protein that facilitates the interaction between the former two [22, 23]. Activation and homooligomerization of NLRP receptor induces the formation of NLRP inflammasomes, which convert precursor caspase- 1 into cleaved caspase- 1 . The cleaved caspase- 1 mediates the inflammatory responses including cleavage and secretion of inflammatory cytokines interleukin- $1 \beta$ (IL-1 $\beta$ ) and interleukin-18 (IL-18), and then initiates the inflammatory form of cell death, referred to as pyroptosis $[20,24]$. Up to now NLRP1 and NLRP3 inflammasomes are the most extensively studied inflammasomes [22, 25, 26]. An online search using a miRNA target prediction software, TargetScan (http://www.targetscan.org/), revealed that miR-125b-2-3p contains nucleotide sequences complementary to the highly conserved seed sequences in the NLRP1 mRNA 3'-UTR (Fig. 7). There are also several previous reports on miR125 as a regulator of NLRP1 mRNA stability [27, 28]. Therefore, we deduce that IRE1 could at least partially regulate the expression level of NLRP1 via miR-125. We hypothesized that IRE1 $\alpha$ inhibition will prevent neuronal pyroptosis via miR-125/NLRP1 pathway in the neonatal HIE rat model.

\section{Material and methods Animals}

All experiments performed in this study were in compliance with the National Institutes of Health guidelines for the handling of laboratory animals and approved by Loma Linda University Institutional Animal Care and Use Committee. Sprague-Dawley rat mothers, with litters of 12 pups, were purchased from Envigo (Livermore, $\mathrm{CA}$ ) and housed in regular light/dark cycle environment with humidity and temperature controlled. Post-natal day 10 (P10) pups, weighing 14-20 g, underwent hypoxia-ischemia surgery. A total of 142 unsexed rat pups were used in this study. Among them, 14 pups were excluded due to death during ischemia surgery or hypoxia induction.

\section{HIE rat model}

The modified Rice-Vannucci method was performed to create the HIE rat model as previously described [29, 30]. Briefly, rat pups were anesthetized with $3 \%$ isoflurane (in mixed air and oxygen) and placed supine to expose the anterior cervical region. The right common carotid artery was separated from surrounding tissues and double ligated using 5-0 surgical silk suture. The artery was cut between the two ligations. The isoflurane exposure time was limited to $8 \mathrm{~min}$. After surgery, pups were allowed to recover for $1 \mathrm{~h}$ and then placed in hypoxia $\left(8 \% \mathrm{O}_{2}\right.$ and $\left.92 \% \mathrm{~N}_{2}\right)$, in an Erlenmeyer flask which was submerged in a $37^{\circ} \mathrm{C}$ water bath, for $2.5 \mathrm{~h}$. After hypoxia, all pups were returned to their dams. Sham pups underwent anesthesia and the exposure of the right common carotid artery, without the ligation and hypoxia.

\section{Intranasal administration}

Pups were placed in a supine position under $2 \%$ isoflurane anesthesia at $1 \mathrm{~h}$ after HI. A total volume of $5 \mu \mathrm{L}$ of STF083010 (45 $\mu \mathrm{g} /$ pup, Abcam) or vehicle (10\% DMSO dissolved in corn oil) was administered intranasally. 
$1.25 \mu \mathrm{l}$ of STF083010 or vehicle per drop was given every $2 \mathrm{~min}$ in alternating nares.

\section{Intracerebroventricular injection}

The miR- 125 -b-2-3p inhibitor $(0.5 \mathrm{nmol} / \mathrm{pup}$, rno-miR125b-22-3p miRCURY LNA miRNA Power Inhibitor, Qiagen, Cat\#YI04109200-DDA), or the anti-miR control $(0.5 \mathrm{nmol} / \mathrm{pup}$, miRCURY LNA miRNA Power Inhibitor control, Qiagen, Cat\#YI00199006-DDA) was administered to the right lateral ventricle at $24 \mathrm{~h}$ before $\mathrm{HI}$. The intracerebroventricular injection was performed as previously described [30, 31]. Pups were placed in a stereotactic frame under isoflurane anesthesia. A 10- $\mu$ l Hamilton micro syringe needle (Hamilton Company, USA) was inserted from the skull surface at the following coordinates relative to bregma: $1.5 \mathrm{~mm}$ posterior, $1.5 \mathrm{~mm}$ lateral to the bregma, and $1.7 \mathrm{~mm}$ beneath the horizontal plane of the skull. The miR-125-b-2-3p inhibitor or the anti-miR control was infused into the ventricle slowly over $5 \mathrm{~min}$ by a pump, and the needle was kept in place for $10 \mathrm{~min}$ after the end of each injection to prevent liquid reflux. The NLRP1 CRISPR activation plasmid $(0.4 \mu \mathrm{g} / \mathrm{pup}$, NLRP1 SAM guide RNA, Qiagen, Quote\#U8376ED300) or control CRISPR activation plasmid $(0.4 \mu \mathrm{g} / \mathrm{pup}$, NLRP1 SAM guide RNA negative control, Qiagen, Quote\#U8376ED300) was given via intracerebroventricular injection as described above at $24 \mathrm{~h}$ before HI. The time point for miRNA inhibitor and CRISPR injection was selected based on previous literature $[32,33]$. According to the manufacturers' protocol, the phenotypic effects of the products are normally assessed $24-72 \mathrm{~h}$ after delivery. A potentially attractive quality of antagomir targeting of miRNAs is prolonged suppression of the miRNA [34]. Silencing of miRNAs by antagomirs has been reported to last several weeks in the periphery [35] and after injection into the brain [36]. Therefore, we selected $24 \mathrm{~h}$ before $\mathrm{HI}$ as the best time point for intracerebroventricular injection.

\section{Experimental design}

The experiment was designed as follows.

\section{Experiment $I$}

To study the temporal expression and cellular localization of p-IRE1 $\alpha$ after hypoxia-ischemia (HI), rat pups were randomly divided into six groups: sham, HI-6 h, HI-12 h, HI-24 h, HI- 48 h, HI-72 h. $n=6$ per group. Western blot analysis was performed to determine the expression changes of IRE1 $\alpha$ and p-IRE1 $\alpha$. Additional 6 pups in the HI-12h group were used for double immunofluorescence staining to evaluate the colocalization of p-IRE1 $\alpha$ with different cell types.

In addition, western blot analysis and reverse transcription quantitative real-time polymerase chain reaction (RT-qPCR) were performed to evaluate the temporal expression of NLRP1, cleaved caspase-1, IL-1 $\beta$, IL-18, and miR-125-b-2-3p at various time points after $\mathrm{HI}$ (groups were assigned same to that of p-IRE1 $\alpha$ time course detection).

\section{Experiment II}

To evaluate the neuroprotective effects of IRE1 $\alpha$ inhibitor, STF083010, after HI, rat pups were randomly divided into 3 groups: sham, HI + vehicle (10\% DMSO dissolved in corn oil), HI + STF083010. $n=18$ per group, 6 pups for TTC staining and western blot, 6 pups for RT-qPCR, and 6 pups for immunofluorescence in each group. Western blot analysis, immunofluorescence, RT-qPCR, neurobehavioral tests, 2,3,5-Triphenyltetrazoliumchloride (TTC), and Fluoro-Jade $\mathrm{C}$ staining were performed to evaluate the infarct volume, neurological performance, the number of degenerating neurons, and the expression changes of miR-125-b-2-3p at 48 after HI with STF083010 treatment. In addition, double immunofluorescence staining was performed to determine the localization and expression changes of the inflammatory cytokines IL-1 $\beta$ and IL-18.

\section{Experiment III}

To explore whether miR-125-b-2-3p was involved in the underlying mechanisms of STF083010 mediated neuroprotective effects, antimiR-125 was used to inhibit miR125-b-2-3p. Rat pups were randomly divided into 5 groups: sham, HI + vehicle, HI + STF083010, HI + STF083010 + antimiR control, HI + STF083010 + miR125 inhibitor. $n=12$ per group, 6 pups for TTC staining and western blot, 6 pups for RT-qPCR in each group. miR-125-b-2-3p inhibitor was intracerebroventricularly injected at $24 \mathrm{~h}$ before HI. TTC staining, neurobehavioral tests, western blot analysis, and RT-qPCR were examined at $48 \mathrm{~h}$ after $\mathrm{HI}$.

\section{Experiment IV}

To explore whether NLRP1 was involved in the underlying mechanism of STF083010-mediated neuroprotective effects, NLRP1 activation CRISPR was used to activate NLRP1. Rat pups were randomly divided into 5 groups: sham, HI + vehicle, HI + STF083010, HI + STF083010 + CRISPR control, HI + STF083010 + NLRP1 CRISPR. $n=6$ per group. NLRP1 activation CRISPR was intracerebroventricularly injected at $24 \mathrm{~h}$ before HI. TTC staining, neurobehavioral tests, and western blot analysis were examined at $48 \mathrm{~h}$ after $\mathrm{HI}$.

\section{Neurobehavioral tests}

Negative geotaxis test was performed to evaluate the neurological function at 48 after $\mathrm{HI}$ by two blinded investigators in an unbiased setup. The pups were placed 
head downward on a $45^{\circ}$ inclined board, and the time taken for the pups to turn to head upward was recorded. The maximum testing time was $60 \mathrm{~s}$, and the time taken more than $60 \mathrm{~s}$ was recorded as $60 \mathrm{~s}$.

\section{Infarct volume measurement}

At $48 \mathrm{~h}$ after HI, TTC staining was used to evaluate the infarct volume as previously described [30]. The rat pup brains were cut into $2-\mathrm{mm}$ coronal sections in a rat brain matrix. The sections were incubated with $2 \%$ TTC solution (Sigma Aldrich Inc., USA) for $5 \mathrm{~min}$ at room temperature and then washed by phosphate-buffered saline (PBS). The sections were imaged, and the volume of the infarct area was quantified and analyzed with the Image J software (NIH, USA). The percentage of infarcted area for each section was calculated as [(total area of contralateral hemisphere) - (area of un-infarcted area of ipsilateral hemisphere)]/(total area of contralateral hemisphere $\times 2$ ). The average value of each section in one brain was taken to represent the percentage of infarcted volume for that pup.

\section{Tissue processing}

Pups were anesthetized with isoflurane and transcardially perfused with $4{ }^{\circ} \mathrm{C}$ PBS and $10 \%$ formalin. The brains were removed and post-fixed with formalin for $48 \mathrm{~h}$ and then immersed in 30\% sucrose until they sank. After being embedded into OCT compound (Scigen Scientific) and frozen, the brains were sliced into serial 10$\mu \mathrm{m}$-thick coronal slices using a cryostat (CM3050S-3, Leica Microsystems) at $-20^{\circ} \mathrm{C}$. The brain slices were prepared for immunofluorescence and Fluoro-Jade C staining as follows.

\section{Immunofluorescence staining}

The slices were rinsed with PBS for $30 \mathrm{~min}$ and permeabilized with $0.3 \%$ Triton X-100 for $30 \mathrm{~min}$ at room temperature [37]. The slices were then rinsed with PBS for $15 \mathrm{~min}$ and blocked with $5 \%$ donkey serum at $37^{\circ} \mathrm{C}$ for $30 \mathrm{~min}$. Subsequently, each coronal slice was incubated with primary antibodies at $4{ }^{\circ} \mathrm{C}$ overnight. The primary antibodies used are as follows: rabbit anti-p-IRE1 $\alpha$ (1:50, Abcam), mouse anti-NeuN (1:200, Santa Cruz Biotechnology), mouse anti-GFAP (1:100, Santa Cruze Biotechnology), and mouse anti-Iba-1(1: 200, Wako). Slices were rinsed in PBS for $15 \mathrm{~min}$ and then incubated with appropriate fluorescence-conjugated secondary antibodies at $37^{\circ} \mathrm{C}$ for $1 \mathrm{~h}$. After being rinsed in PBS for 15 min, the slices were covered with Vectashield Antifade Mounting Medium with DAPI (Vector Laboratories Inc.). Images were then visualized under a fluorescence microscope (Leica DMi8, Leica Microsystems).

\section{Fluoro-Jade C staining}

Fluoro-Jade C staining (FJC) was used to identify and quantify degenerating neurons. The staining was performed at $48 \mathrm{~h}$ post $\mathrm{HI}$ with the Fluoro-Jade C Ready-to-Dilute Staining Kit (Biosensis) following the manufacturer's instructions. The number of FJC positive cells was counted manually in the peri-ischemic regions. The data was expressed as positive cells per $\mathrm{mm}^{2}$ and six sections per brain over a microscopic field of $\times 20$ were picked to be averaged.

\section{Reverse transcription real-time quantitative polymerase chain reaction ( $\mathrm{RT}$ q-PCR)}

Total RNA extraction was isolated according to miRNeasy Mini Kit (Qiagen) instructions, and $2 \mu \mathrm{g}$ of RNA in each group was reverse transcribed with miScript II RT kit (Qiagen) to generate cDNA. The expressions of miR-125-b-2-3p relative to SNORD61, an internal reference gene, were determined by SYBR-Green PCR method with miScript Primer Assay kit (Qiagen) according to manufacturer's instructions. The primer of miR125-b-2-3p was Rn-miR-125b*-2 miScript Primer Assay (Qiagen, Cat\#MS000033201) and that of SNORD61 was Hs-SNORD61-11 miScript Primer Assay (Qiagen, Cat\#MS00033705). The PCR reaction mixture consisted of $12.5 \mu \mathrm{l} 2 \times$ QuantiTect SYBR Green PCR Master Mix, $2.5 \mu \mathrm{l} 10 \times$ miScript Universal Primer, $2.5 \mu \mathrm{l} 10 \times \mathrm{miS}-$ cript Primer Assay, $2 \mu \mathrm{l}$ of template cDNA, and RNasefree water to a total volume of $25 \mu \mathrm{l}$. Cycling conditions were $95^{\circ} \mathrm{C}$ for $15 \mathrm{~min}$ as an initial activation step, followed by 40 cycles: denaturation at $95^{\circ} \mathrm{C}$ for $15 \mathrm{~s}$, annealing at $55^{\circ} \mathrm{C}$ for $30 \mathrm{~s}$, and extension at $70{ }^{\circ} \mathrm{C}$ for $30 \mathrm{~s}$. PCR specificity was confirmed by melt curve analysis. The relative fold change in miR-125-b-2-3p expression was calculated using the comparative cycle threshold method $\left(2^{-\Delta \Delta C T}\right)[38]$.

\section{Western blot analysis}

After TTC staining and digitally photographed at $48 \mathrm{~h}$ after HI, the brain sections were separated into contralateral and ipsilateral hemispheres immediately. The ipsilateral hemisphere samples were snap-frozen in liquid nitrogen and stored at $-80^{\circ} \mathrm{C}$ for further use. The brain samples were homogenized in RIPA lysis buffer (Santa Cruz Biotechnology) with protease inhibitor cocktail for $15 \mathrm{~min}$ and then centrifuged at $14,000 \mathrm{~g}$ at $4{ }^{\circ} \mathrm{C}$ for 30 min, the whole cell lysates were collected. The protein concentration was determined by using a detergent compatibility assay ( $\left(C^{\mathrm{TM}}\right.$ Protein Assay, Bio-Rad). Equal amounts of proteins were loaded onto $10 \%$ sodium dodecylsulfate polyacrylamide gel electrophoresis (SDSPAGE) gels for electrophoresis, and proteins were then transferred onto nitrocellulose membranes. The membranes were blocked for $2 \mathrm{~h}$ at $37^{\circ} \mathrm{C}$ with $5 \%$ non-fat 
milk, followed by incubation at $4{ }^{\circ} \mathrm{C}$ overnight with the primary antibodies: anti-p-IRE1 $\alpha$ (1:500, Abcam), antiIRE1 $\alpha$ (1:500, Abcam), anti-NLRP1 (1:1000, Abcam), anti-cleaved caspase-1 (1:500, Novus Biologicals), antiIL-1 $\beta$ (1:1000, Abcam), anti-IL-18 (1:1000, Abcam), and anti- $\beta$-actin (1:3000, Santa Cruz Biotechnology). The membranes were then incubated for $1 \mathrm{~h}$ at $37^{\circ} \mathrm{C}$ with horseradish peroxidase-conjugated secondary antibodies (Santa Cruz Biotechnology). Bands were visualized using ECL Plus kit (American Bioscience, UK) and quantified through the Image J software. The density of each protein of interest was normalized against the density of the $\beta$-actin band.

\section{Statistical analysis}

Statistical analysis was performed using the GraphPad Prism 7.01 software. The data were presented as mean \pm SD. Differences between individual groups were determined with one-way ANOVA analysis of variance followed by post hoc tests with Tukey's multiple comparisons. Differences between two groups were compared using Student's $t$ test. All reported $P$ values were two-sided, and a value of $P<0.05$ was considered statistically significant [39].

\section{Results}

Spatial expression and time course of endogenous $p$ IRE1a expression after $\mathrm{HI}$

Double immunofluorescence staining of $p-I R E 1 \alpha$ with NeuN, Iba-1, and GFAP was performed at $12 \mathrm{~h}$ post HI. Colocalization of p-IRE1 $\alpha$ with NeuN, Iba1 , and GFAP were detected in ipsilateral peri-infarct cortex (Fig. 1a). These results indicated that IRE1 $\alpha$ was extensively expressed on neurons, microglia, and astrocytes. Analysis of the western blot bands showed that the ratio of $\mathrm{p}-\mathrm{IRE} 1 \alpha / \mathrm{IRE} 1 \alpha$ expression increased in a time-dependent manner, reaching peak at $12 \mathrm{~h}$ after HI $(P<0.05$ compared to sham group, Fig. 1b, c).

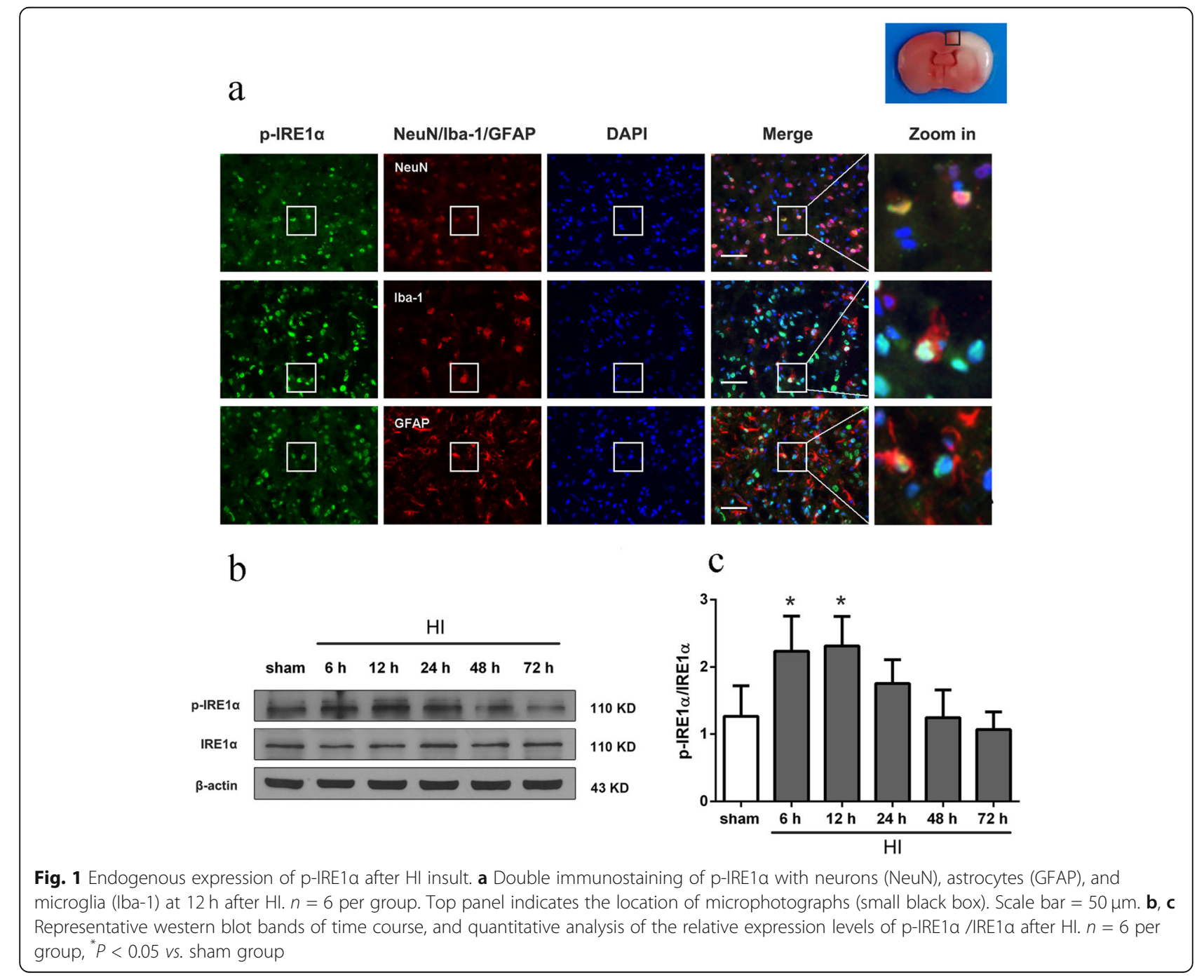


Expression changes of NLRP1, cleaved caspase-1, IL-1 $\beta$, IL-18, and miR-125-b-2-3p after HI

Analysis results of the western blot bands showed the expression level of NLRP1, cleaved caspase-1, IL-1 $\beta$, and IL18 dramatically increased after $\mathrm{HI}$ induction and reached to the highest level at $12 \mathrm{~h}$ or $24 \mathrm{~h}$ post $\mathrm{HI}(P<0.05 \mathrm{com}-$ pared to sham group, Fig. $2 \mathrm{a}-\mathrm{e})$. These results indicated that the NLRP1 inflammasome was activated and neuronal cell pyroptosis occurred in the HIE rat model.

RT-qPCR results showed that the expression level of miR-125-b-2-3p dramatically decreased after HI induction and reached to the lowest level at $48 \mathrm{~h}$ post HI $(P<0.05$ compared to sham group, Fig. 2f).

Intranasal administration of STF083010 reduced infarct volume, improved short-term neurological functions, reduced neuronal degeneration, and upregulated miR125-b-2-3p expression at $48 \mathrm{~h}$ after $\mathrm{HI}$

TTC staining results showed that there was no infarct region in sham group. HI insults lead to the obvious infarct area in vehicle group, while intranasal administration of STF083010 reduced the infarct volume when compared with vehicle group $(P<0.05$, Fig. 3a, b).

The Geotaxis reflex time in vehicle group was increased significantly when compared with sham group at $48 \mathrm{~h}$ after $\mathrm{HI}$, while it decreased significantly in STF083010 treatment group when compared with vehicle group $(P<0.05$, Fig. $3 c)$.

Robust FJC staining in ipsilateral peri-infarct cortex was observed at $48 \mathrm{~h}$ after $\mathrm{HI}$ in vehicle group, while STF083010 treatment significantly reduced the number of FJC-positive neurons when compared with vehicle group $(P<0.05$, Fig. $3 d$, e).
RT q-PCR data showed that the expression of miR$125-b-2-3 p$ significantly decreased in vehicle group when compared with sham group $(P<0.05)$, while STF083010 treatment upregulated the expression of miR-125-b-2-3p when compared with vehicle group $(P<0.05$, Fig. $3 f)$.

These results indicated that IRE1- $\alpha$ inhibition reduced infarct volume, improved short-term neurological function, reduced neuronal degeneration, and upregulated miR-125-b-2-3p expression after HI.

\section{Intranasal administration of STF083010 downregulated} the expression level of IL-1 $\beta$ and IL-18 at $48 \mathrm{~h}$ after $\mathrm{HI}$ Immunofluorescence staining showed that the fluorescent intensity of IL- $1 \beta$ and IL-18 on neurons, astrocytes, and microglia, in vehicle group, was increased when compared with sham group, while the fluorescent intensity of the two inflammatory cytokines decreased in STF083010 treatment group when compared with the vehicle group. IL-1 $\beta$ and IL-18 were expressed extensively on neurons, microglia, and astrocytes (Fig. 4, Fig. 5). These results indicated that IRE1- $\alpha$ inhibition reduced cell pyroptosis after $\mathrm{HI}$.

\section{Inhibition of miR-125-b-2-3p attenuated the neuroprotective effects induced by STF083010 treatment at $48 \mathrm{~h}$ post $\mathrm{HI}$}

To determine the role of miR-125-b-2-3p in STF083010 neuroprotective effects, we used antimiR-125 to inhibit miR-125-b-2-3p. TTC staining results showed that the infarct volume increased significantly in $\mathrm{HI}+$ STF083010 + antimiR-125 group when compared with the $\mathrm{HI}+$ STF083010 + miR inhibitor control group. The Geotaxis reflex time increased in HI + STF083010+
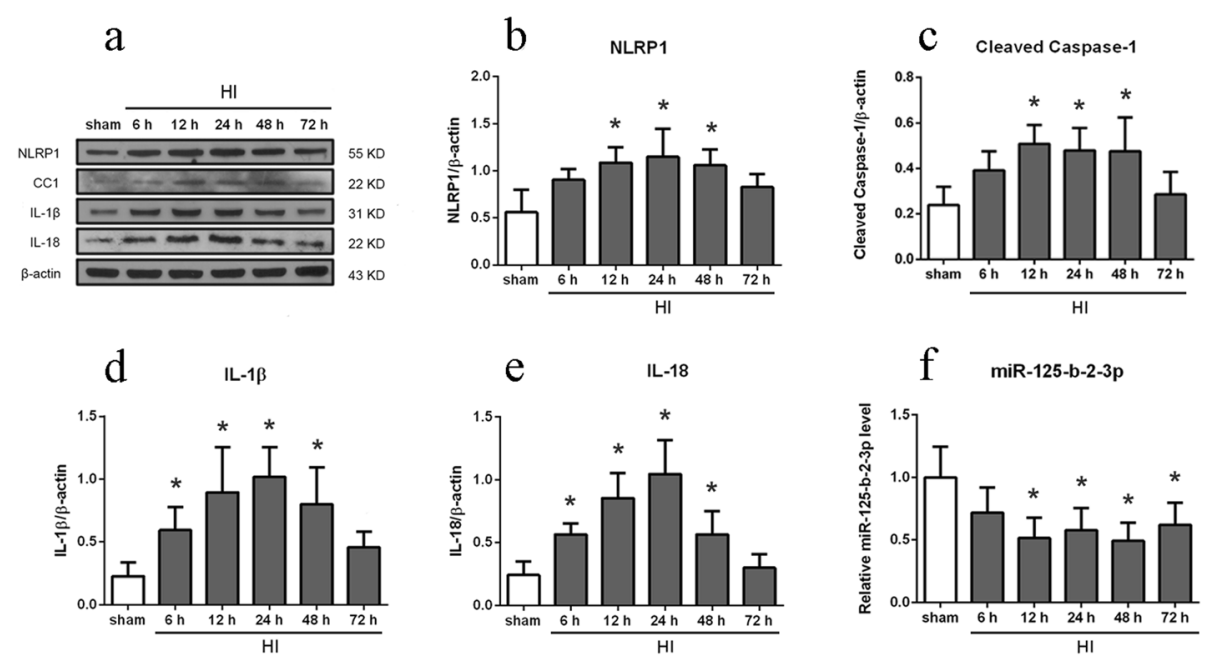

Fig. 2 Endogenous expression of NLRP1, cleaved caspase-1, IL-1 3 , IL-18, and miR-125-b-2-3p after HI insult. a-e Representative western blot bands of time course, and quantitative analysis of the relative expression level of proteins NLRP1, cleaved caspase-1 (CC1), IL-1 $\beta$, and IL-18 after HI insult, $n=6$ per group. $\mathbf{f}$ Expression of endogenous miR-125-b-2-3p after $\mathrm{HI}$ insult determined by real time PCR detection, $n=6$ per group. ${ }^{*} P<$ 0.05 vs. sham group 
a
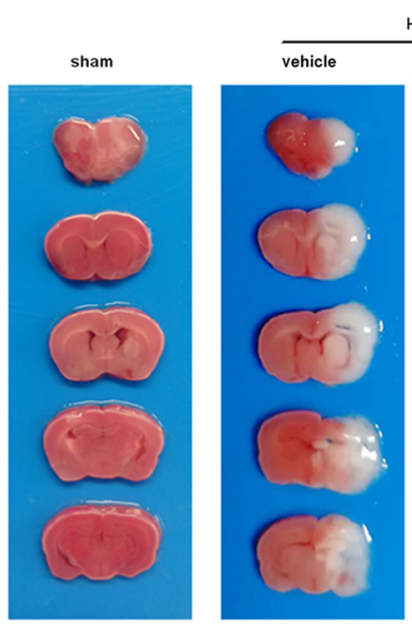
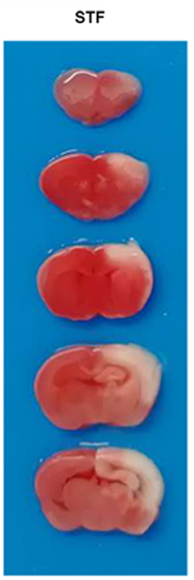

$\mathrm{b}$

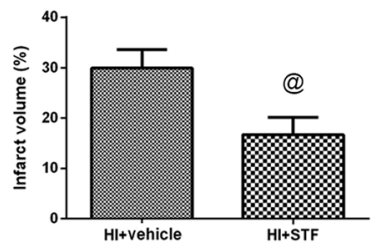

C

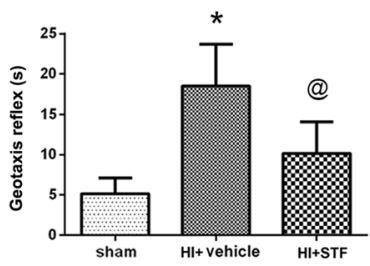

d
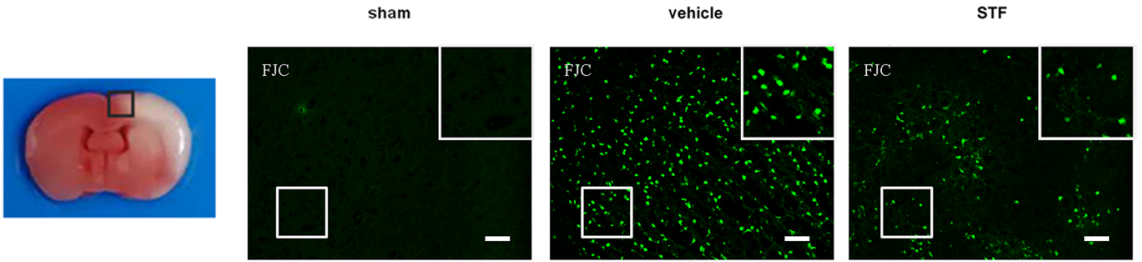

e

f
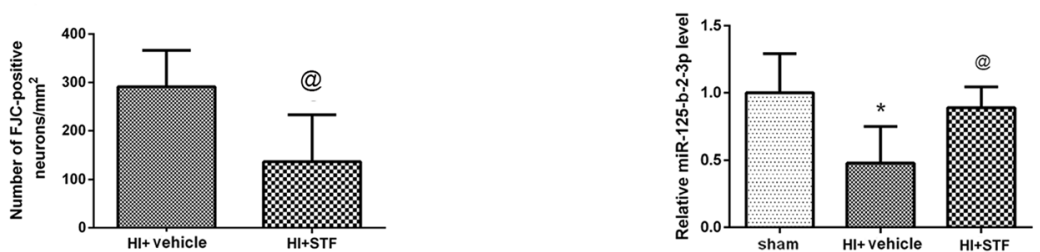

Fig. 3 Effect of intranasal administration of STF083010 on brain infarct volume, neuronal degeneration, neurological function and the relative miR-125-b-2-3p expression level. a Representative TTC staining photographs. b Analysis of infarct volume. c Analysis of reflex time in Geotaxis test. d Representative Fluoro-Jade C staining (FJC) photographs. Left panel indicates the location of microphotographs (small black box). The white box at right upper corner in each FJC staining photographs is the magnification of that at left lower corner. Scale bar $=100 \mu \mathrm{m}$.

e Analysis of the number of FJC-positive neurons in the FJC staining photographs. $\mathbf{f}$ Quantitative analysis of the relative expression level of miR-125b-2-3p in real time PCR tests. Data are represented as means \pm SD. $n=6$ for each group. ${ }^{*} P<0.05$ vs. sham group; ${ }^{\circledR} P<0.05$ vs. $\mathrm{HI}+$ vehicle group

antimiR-125 group when compared with the $\mathrm{HI}+$ STF083010 + miR inhibitor control group $(P<0.05$, Fig. 6). These results indicated that miR-125-b-2-3p was involved in the neuroprotective effects induced by IRE1- $\alpha$ inhibition.

Inhibition of miR-125-b-2-3p reversed the downregulation of NLRP1, cleaved caspase-1, IL-1 $\beta$, and IL-18 induced by STF083010 treatment at $48 \mathrm{~h}$ post $\mathrm{HI}$

RT q-PCR data showed the expression level of miR125-b-2-3p decreased significantly in HI + STF083010
+ antimiR-125 group when compared with the $\mathrm{HI}+$ STF083010 + miR inhibitor control group $(P<0.05$, Fig. 7a).

Western blot data showed that the expression level of NLRP1, cleaved caspase-1, IL-1 $\beta$, and IL-18 increased significantly in $\mathrm{HI}+$ vehicle group when compared with the sham group, and then decreased significantly in $\mathrm{HI}+$ STF083010 group when compared with the $\mathrm{HI}+$ vehicle group. These proteins increased significantly in $\mathrm{HI}+$ STF083010 + antimiR-125 group when compared with the HI + STF083010 + miR inhibitor control group $(P<0.05$, Fig. 8). 


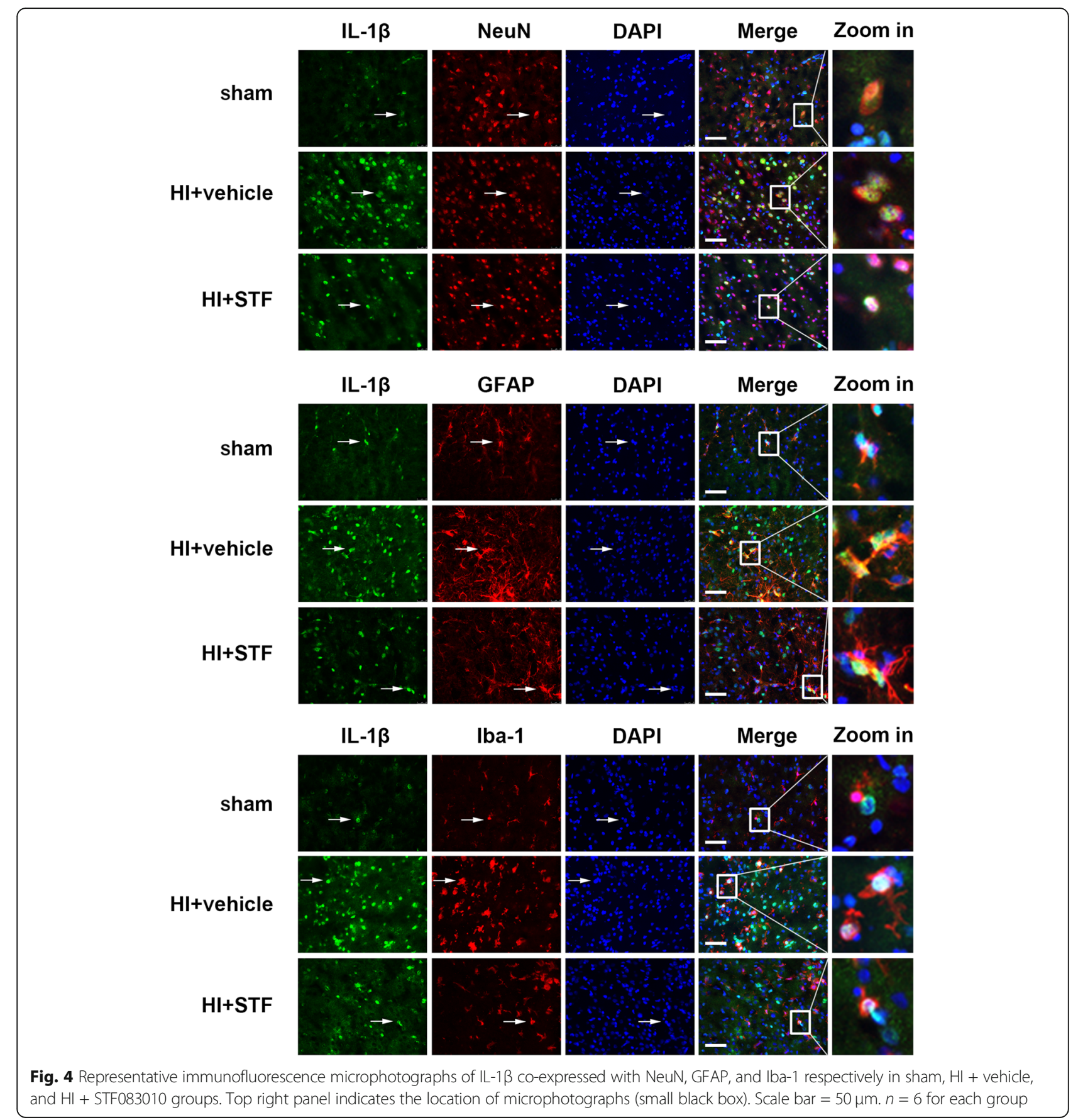

These results indicated that miR-125-b-2-3p plays an important protective role against ER stress-induced cell pyroptosis.

NLRP1 activation CRISPR attenuated the neuroprotective effects induced by STF083010 treatment at $48 \mathrm{~h}$ post $\mathrm{HI}$ To explore whether NLRP1 was involved in the mechanism of STF083010 neuroprotective effects, we used NLRP1 activation CRISPR to activate NLRP1 expression.
TTC staining results showed the infarct volume increased significantly in HI + STF083010 + NLRP1 activation CRISPR group when compared with the HI + STF083010 + CRISPR control group. The Geotaxis reflex time increased in HI + STF083010 + NLRP1 activation CRISPR group when compared with the HI + STF083010 + CRISPR control group $(P<0.05$, Fig. 6). These results indicated that NLRP1 inflammasome was involved in the neurological injury induced by IRE-1 $\alpha$ activation. 


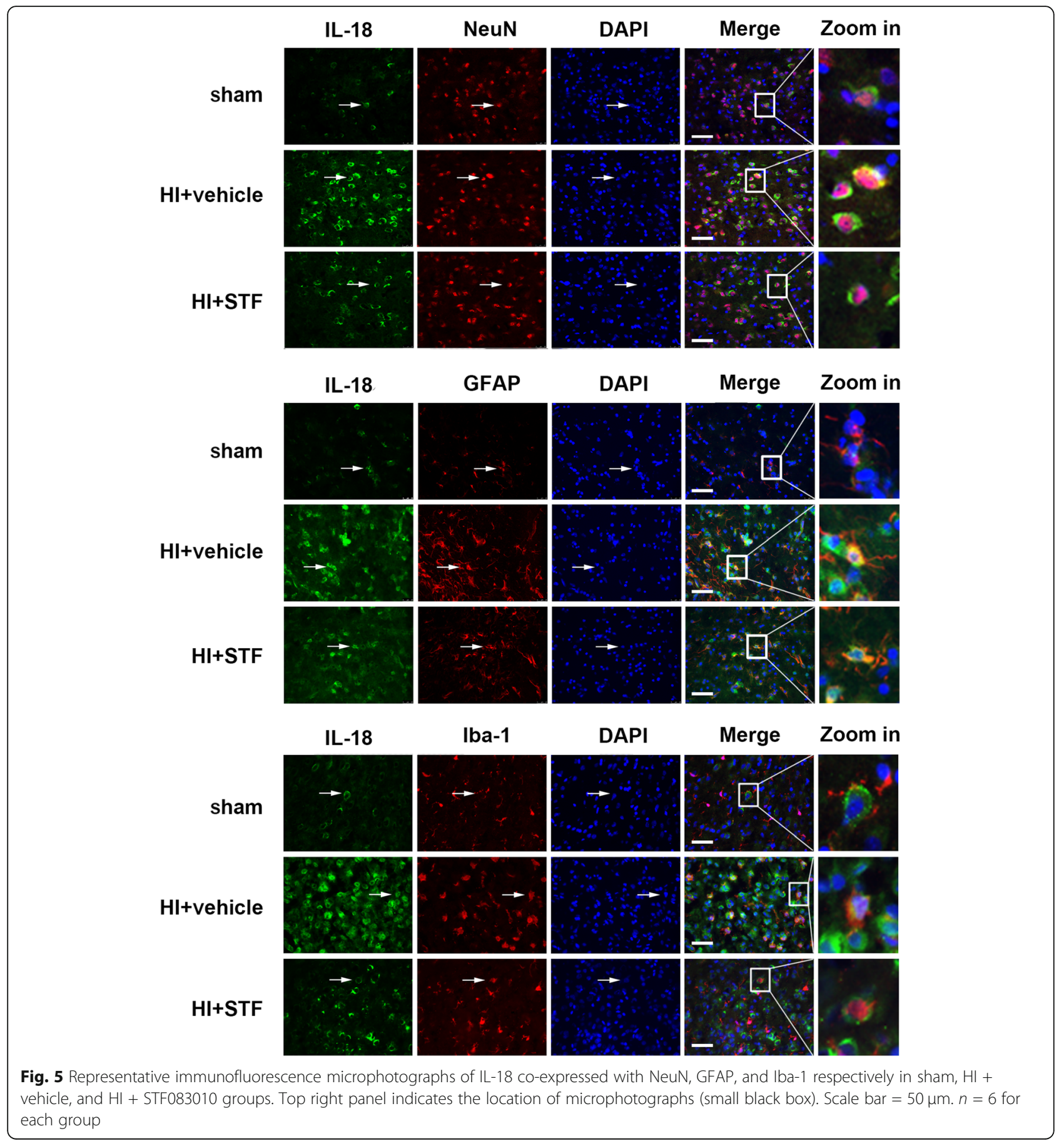

NLRP1 activation CRISPR reversed the downregulation of NLRP1, cleaved caspase-1, IL-1 $\beta$, and IL-18 induced by STF083010 treatment at $48 \mathrm{~h}$ post $\mathrm{HI}$

Western blot data showed that the expression level of NLRP1, cleaved caspase-1, IL-1 $\beta$, and IL-18 increased significantly in $\mathrm{HI}+$ vehicle group when compared with the sham group, and then decreased significantly in $\mathrm{HI}+$ STF083010 group when compared with the $\mathrm{HI}+$ vehicle group. These proteins increased significantly in $\mathrm{HI}+$
STF083010 + NLRP1 activation CRISPR group when compared with the HI + STF083010 + CRISPR control group $(P<0.05$, Fig. 9). These results indicated that NLRP1 inflammasome was involved in ER stressinduced cell pyroptosis after HI.

\section{Discussion}

The activation of several different neuronal cell death pathways, including apoptosis, autophage, pyroptosis, 

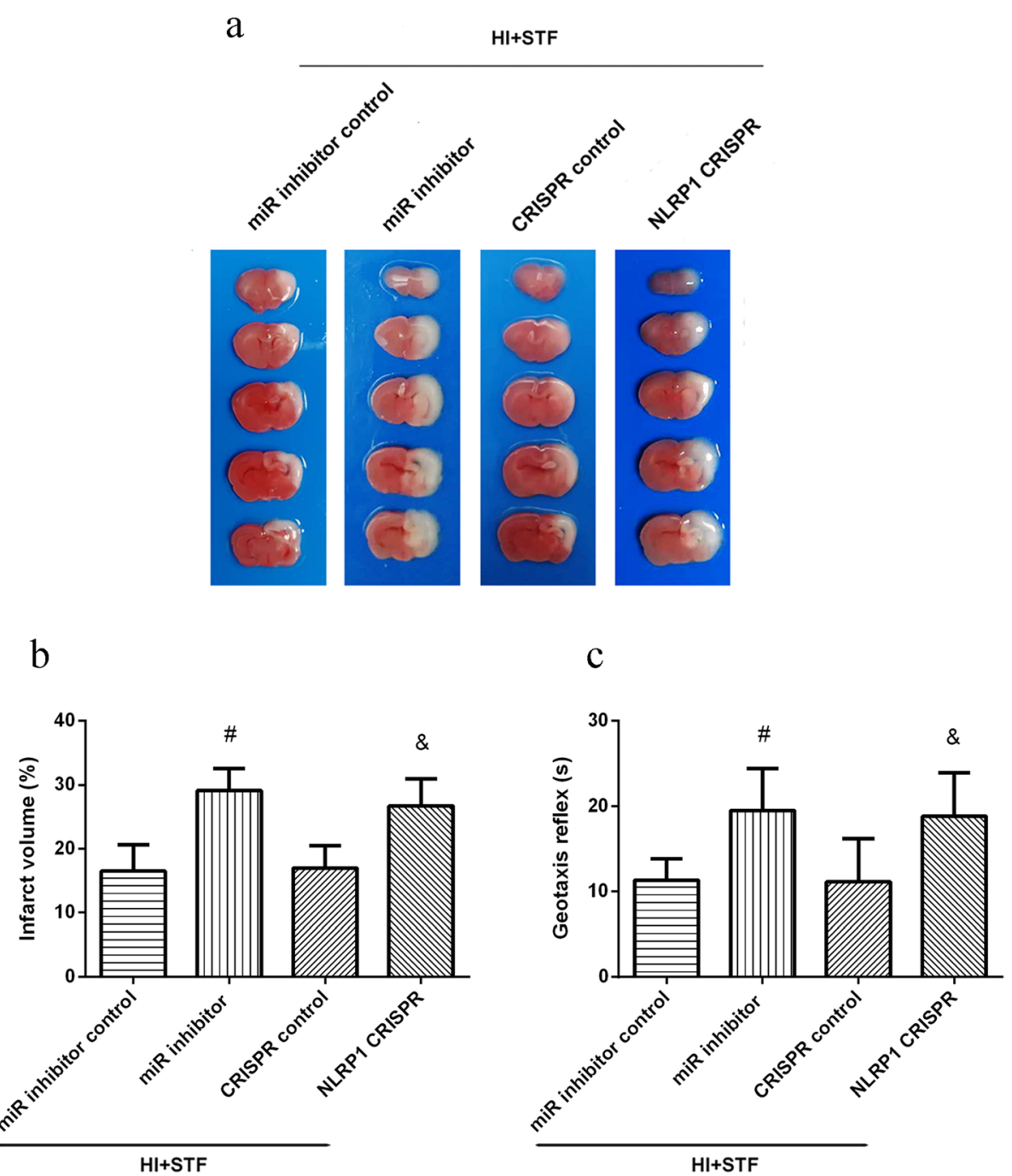

Fig. 6 Effects of miR-125 inhibitor and NLRP1 CRISPR on infarct volume and neurological function at $48 \mathrm{~h}$ post HI. a Representative TTC staining photographs. $\mathbf{b}$ Analysis of infarct volume. $\mathbf{c}$ Analysis of reflex time in Geotaxis test. Data are represented as means \pm SD. $n=6$ for each group. ${ }^{\#} P<0.05$ vs. HI + STF083010 + miR inhibitor control group; ${ }^{\&} P<0.05$ vs. HI + STF083010 + CRISPR control

necrosis, excitotoxic cell death, etc., account for the brain damages that occur after hypoxia-ischemic (HI) insults [40-43]. Recently, the contribution of neuronal pyroptosis in the process of HIE pathophysiology is drawing much more attention and many researchers have tried to reduce neural damage by reversing the occurrence of neuronal pyroptosis in HIE [41, 44, 45]. NLRP1 was the first inflammasome to be characterized and was reported to promote pyroptosis in neurons [22, 46]. The core complex of NLRP1 inflammasome is composed of NLRP1, ASC (apoptosis-associated speck-like protein containing a CARD), caspase 1 , and caspase 5 [22]. In the present study, western blot results showed that the expression level of NLRP1, cleaved caspase-1, IL-1 $\beta$, and IL-18 were increased after HI insult, which indicated that NLRP1 inflammasome was activated and neuronal cell pyroptosis occurred in the HIE rat model. The immunofluorescence results indicated that both inflammatory cytokines, IL-1 $\beta$ and IL-18, were expressed in neurons, microglia, and astrocytes, demonstrating pyroptosis.

ER stress, caused by the clustering of excess misfolded or unfolded proteins in the ER lumen, triggers unfolded protein response (UPR) signaling pathway [47]. Under remediable ER stress, UPR is a protective response aimed at preventing further accumulation of unfolded proteins within the ER and returning the ER to its normal physiological state. However, under severe or prolonged ER stress, UPR switches to leading cell death by activating ER-associated apoptotic pathways [4, 5, 48, 49]. At least three ER-transmembrane proteins, the PKR-like ER kinase (PERK), the activating transcription 


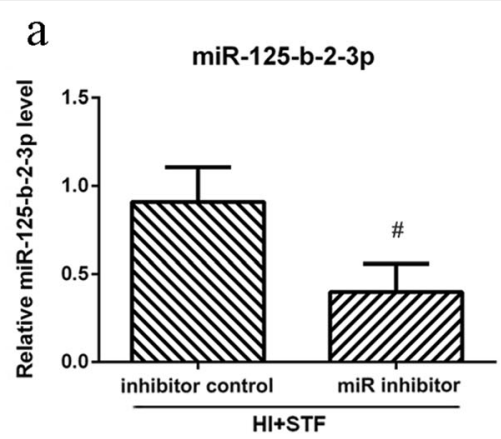

b

\section{Position of 246-252 of NLRP1: $\quad 5$, ...ACUGUGCUGCACCAAGACUUGAG... \\ rno-miR-125b-2-3p : 3' UCCAGGGUUCUCGGACUGAACA}

Fig. 7 Effects of miR-125 inhibitor on miR-125b-2-3p and search results from the TargetScan software. a Quantitative analysis of the relative expression level of miR-125b-2-3p in real time PCR tests. Data are represented as means \pm SD. $n=6$ for each group. ${ }^{\#} P<0.05$ vs. HI+ STF083010 + miR inhibitor control. b Sequence alignment showed putative miR-125b-2-3p binding sites within the $3^{\prime}-U T R$ of the NLRP1 mRNA in rats (http://www.targetscan.org/)

factor-6 (ATF-6), and the inositol-requiring enzyme 1 (IRE1), contain ER luminal stress-sensing domains and carry out the UPR in mammals. IRE1 is the most ancient, evolutionarily conserved UPR sensor, which has two types of isoforms: IRE1 $\alpha$ or $\operatorname{IRE} 1 \beta[11,50,51]$. IRE1 $\alpha$ is expressed extensively in various tissues, whereas IRE1 $\beta$ is only expressed in the digestive system $[11,50]$. Apart from the stress sensor domain, IRE1 $\alpha$ contains a cytosolic serine/threonine kinase domain and an endoribonuclease (RNase) domain as well [47, 52, 53]. Upon ER stress, the IRE1 $\alpha$ kinase domain is dimerized and self-phosphorylated, which consequently activates the RNase domain $[47,54,55]$. The RNase activity of IRE1 $\alpha$ catalyzes the excision of a 26-nt intron within the X-box-binding protein 1 (XBP1) mRNA and results in the formation of spliced XBP1 (XBP1s), which a

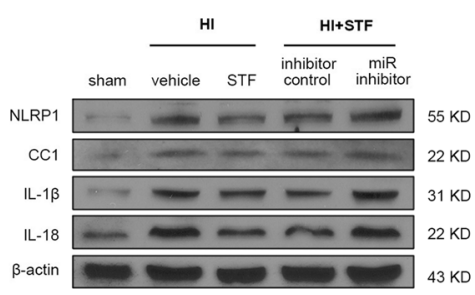

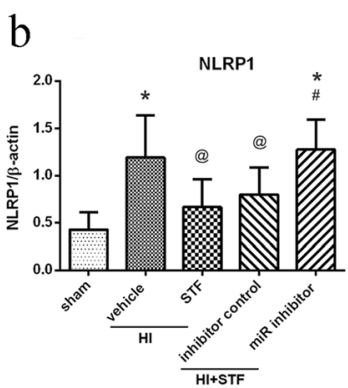
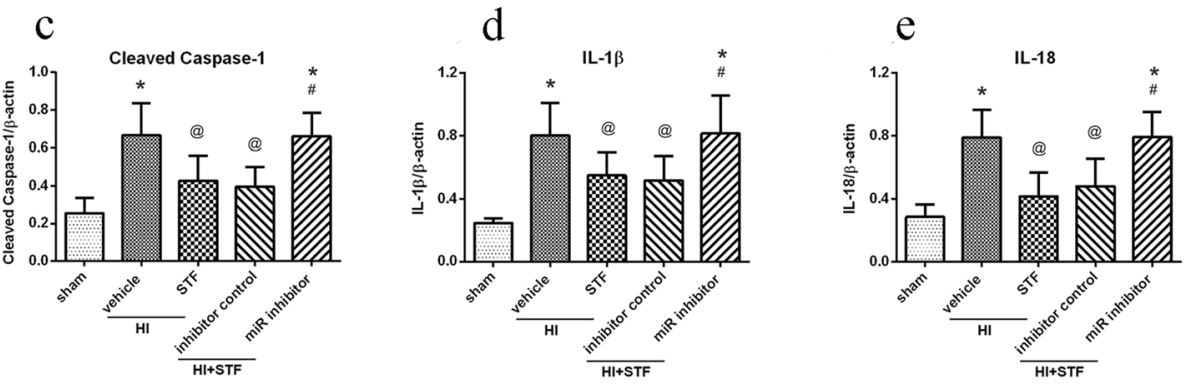

Fig. 8 Effects of miR-125 inhibitor on downstream proteins in proposed signaling pathway with STF083010 treatment at $48 \mathrm{~h}$ post HI. a Representative pictures of the western blot bands of the proteins NLRP1, cleaved caspase-1(CC1), IL-1 $\beta$, and IL-18. b-e Quantitative analysis of the relative expression level of proteins NLRP1, cleaved caspase-1, IL-1 $\beta$, and IL-18. Data are represented as means \pm SD. $n=6$ for each group. ${ }^{*} P<0.05$ vs. sham group; ${ }^{@} P<0.05$ vs. HI + Vehicle; ${ }^{\#} P<0.05$ vs. HI + STF083010 + miR inhibitor control 

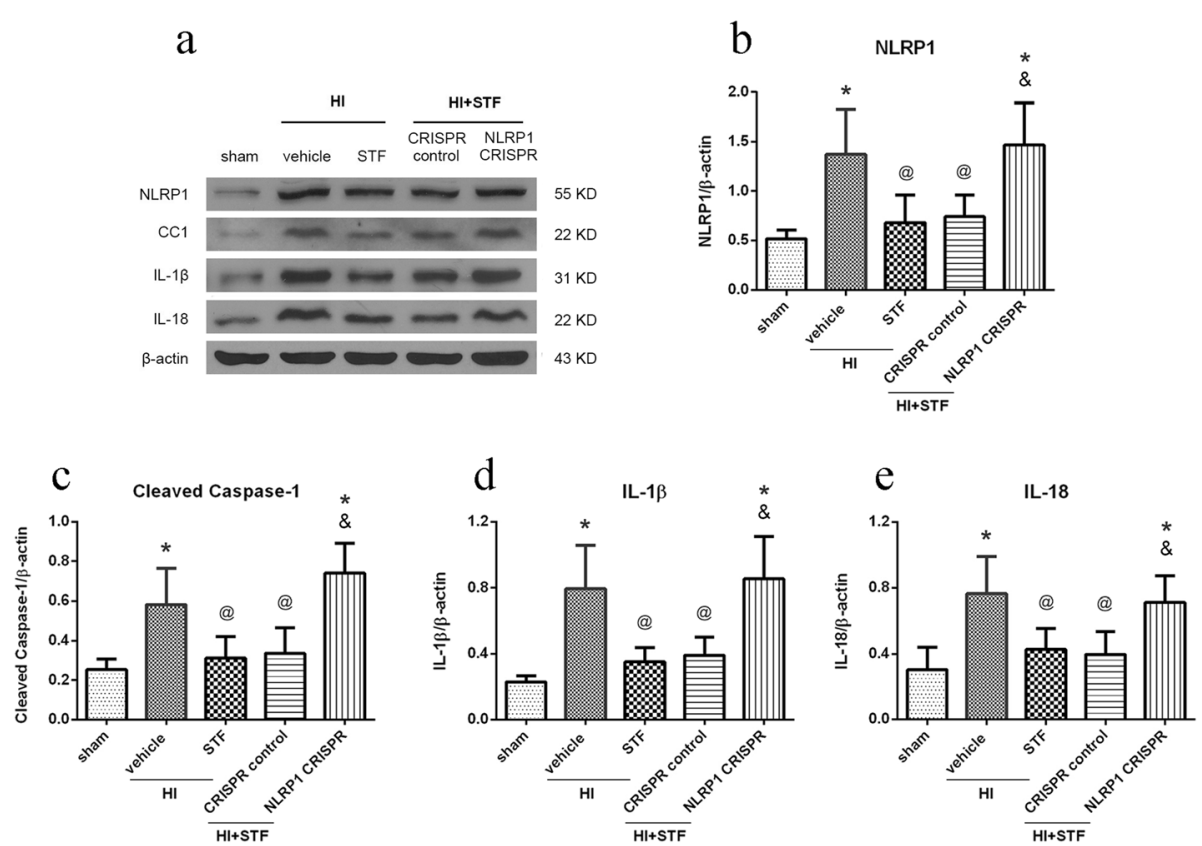

Fig. 9 Effects of NLRP1 activation CRISPR on downstream proteins in proposed signaling pathway with STF083010 treatment at $48 \mathrm{~h}$ post $\mathrm{HI}$. a Representative pictures of the western blot bands of the proteins NLRP1, cleaved caspase-1(CC1), IL-1 $\beta$, and IL-18. b-e Quantitative analysis of the relative expression level of proteins NLRP1, cleaved caspase-1, IL-1 $\beta$, and IL-18. Data are represented as means \pm SD. $n=6$ for each group. ${ }^{*} P<0.05$ vs. sham group; ${ }^{@} P<0.05$ vs. HI + Vehicle; ${ }^{\&} P<0.05$ vs. HI + STF083010 + CRISPR control

transcriptionally promotes the expression of genes responsible for restoring ER folding capacity [56-58]. In addition to its adaptive effects on alleviating unfolded protein accumulation, excessive activation of IRE1 $\alpha$ can switch to promote apoptosis by degrading numerous types of RNA which encode the downstream signal molecules related to apoptosis such as CCAAT/enhancerbinding protein-homologous protein (CHOP) [47, 59, $60]$. In the present study, the results showed that the relative expression level of p-IRE1a peaked at $6 \mathrm{~h}$ and started to decline after $12 \mathrm{~h}$, which is consistent with previous studies $[4,5]$ and indicated that IRE1a activation, after HIE, is an early event.

In our previous study, we explored the optimal dose of STF083010 (45 $\mu \mathrm{g} / \mathrm{pup})$, a specific inhibitor of IRE1 $\alpha^{\prime} \mathrm{s}$ RNAase activity, for treatment in HIE rat model and evaluated STF083010 protective effects by measuring infarct volume and performing neurobehavioral testing at $24 \mathrm{~h}$ and $72 \mathrm{~h}$ after HI insult [5]. Here we complementally observed the treatment effect of the best dose of STF083010 on infarct volume and negative geotaxis test score at $48 \mathrm{~h}$ after $\mathrm{HI}$ insult, which further confirmed that inhibition of the IRE1 $\alpha$ activity could alleviate the brain injury in HIE rat model.

Severe ER stress is associated with multiple types of tissue damage, including excitotoxicity injury, oxidative stress, and neuronal apoptosis [61-63]. For example, the accumulation of excessive unfolded proteins within the
ER leads to the hyperfusion of mitochondria and initiates mitochondria-mediated apoptosis in cells [64]. It was founded that IRE1 $\alpha$ inhibition reduced the number of FJC-positive neurons in the present study, which indicates that severe ER stress is responsible for the degeneration of neurons in HIE rat model. The factors accounting for the degeneration of neurons include neuronal apoptosis, necrosis, pyroptosis, etc. [65-67]. The type of cell death, which associates ER stress with neurodegeneration, is an issue that needs in-depth investigation. Here, we focused on the relationship between ER stress process with neuronal pyroptosis and found that inhibition of IRE1 $\alpha$ leads to the decreased expression of cleaved caspase-1, IL-1 $\beta$, and IL-18. These results indicate that ER stress could initiate neuronal injury through inducing neuronal pyroptosis in HIE rat model. In our study, we demonstrated ER stress-induced neuronal pyroptosis; however, the role of other ER stress-induced signaling pathways which leads to the brain injury through oxidative stress or excitotoxicity needs to be further evaluated.

The cytosolic pattern-recognition receptors that form the inflammasomes in the central nervous system (CNS) are either a member of the PYHIN (pyrin and HIN domain-containing) family of proteins or a member of the NLRs (NOD-like receptors) family proteins [22]. The members of PYHIN family proteins consists of absent in melanoma 2 (AIM2) and interferon-inducible protein 
16(IFI16), and those of NLRs family are comprised of NLRP1 (NOD-, LRR- and pyrin domain-containing 1), NLRP2, NLRP3, NLRP6, NLRP12, and NLRC4 (activation and recruitment domain -containing 4) [22]. Among the above numerous inflammasomes, NLRP1 and NLRP3 were extensively studied. In our previous study, we showed that destabilizing the NLRP3/TXNIP inflammasome led to neuroprotection after HIE [5]. In our present study, we demonstrated that inhibition of IRE1 $\alpha$ downregulated the expression of NLRP1 in HIE model. Moreover, NLRP1 activation CRISPR reversed STF083010s effects by upregulating the expressions of cleaved caspase-1, IL-1 $\beta$, and IL-18 after HI insult. These results suggest that NLRP1 inflammasome may contribute to neuronal pyroptosis induced by IRE1 $\alpha$ activation after HIE. In addition to the activation of IRE1 $\alpha$, there are two other transmembrane sensor proteins, PERK and ATF-6, that can be activated as well in the course of the UPR. Whether activation of the other two UPR sensor proteins, PERK and ATF-6, also lead to the downstream pathways related to the formation of cytosolic inflammasomes and neuronal pyroptosis is worth of study in the future.

Recent studies have shown that miR-125 plays important roles in regulating cancer proliferation, invasion, angiogenesis, liver regeneration, etc. [68-71]. In this study, the expression of p-IRE1 $\alpha$ was increased and miR-125 was decreased in HIE rat model; while the expression of miR-125 was upregulated after inhibition of IRE-1 $\alpha$ activity. These results suggest that the activation of IRE- $1 \alpha$ promotes the degradation of miR-125, which is consistent with previous reports [13]. Considering NLRP1 being upregulated after miR-125 was inhibited, and that a nucleotide sequence in the NLRP1 3' UTR might be targeted by miR-125 in the search results of TargetScan software, we drew the conclusion that miR-125 acts as a bridge between the RNase activity of IRE1 $\alpha$ and the stability of NLRP1 inflammasome. The decay of miR-125 caused by IRE1 $\alpha$ activation in HIE model leads to the occurrence of neuronal pyroptosis through promoting the formation of NLRP1 inflammasomes.

\section{Conclusions}

In conclusion, this study demonstrated that inhibition of the excessive RNase activity of IRE1 $\alpha$ is protective in part via the miR-125/NLRP1 signaling pathway in neonatal HIE rat model, and IRE1 $\alpha$ inhibitor acts to reverse the neuronal pyroptosis post HIE. Elucidating extensively the signaling pathway involved in neuronal pyroptosis in the UPR process is important for future novel treatment targets to reduce neuronal injury caused by irreversible ER stress post HIE.

\section{Abbreviations}

AIM2: Absent in melanoma 2; ATF-6: Activating transcription factor-6; CC1: Cleaved caspase-1; CHOP: CCAAT/enhancer-binding proteinhomologous protein; CNS: Central nervous system; ER: Endoplasmic reticulum; FJC: Fluoro-Jade C; GFAP: glial fibrillary acidic protein; HI: Hypoxiaischemia; HIE: Hypoxic-ischemic encephalopathy; Iba-1: lonized calcium binding adaptor molecule-1; IFI16: Interferon-inducible protein 16; IL: Interleukin; IRE1a: Inositol requiring enzyme-1 alpha; miRNAs: MicroRNAs; miR-125-b-2-3p: MicroRNA-125-b-2-3p; NeuN: Neuronal nuclei; NLRP1: NOD-, LRR- and pyrin domain-containing 1; NOD: Nucleotide-binding oligomerization domain; PERK: PKR-like ER kinase; p-IRE1a: Phosphorylated inositol requiring enzyme-1 alpha; PYHIN: Pyrin and HIN domain-containing; RNase: Endoribonuclease; RT-qPCR: Reverse transcription quantitative realtime polymerase chain reaction; SDS-PAGE: Sodium dodecylsulfate polyacrylamide gel electrophoresis; TTC: 2,3,5-Triphenyltetrazoliumchloride; UPR: Unfolded protein response; XBP1: X-box-binding protein 1; XBP1s: Spliced XBP1

\section{Acknowledgements}

Not applicable.

\section{Authors' contributions}

$J H, D M D, J T$, and JHZ conceptualized and designed the study. JH and MG performed the HI surgeries, intranasal administration, and RT-qPCR experiments. $\mathrm{JH}$ and $\mathrm{WL}$ performed the intracerebroventricular injection, western blotting, and immunofluorescence experiments. $\mathrm{XH}$ and $\mathrm{RL}$ assisted $\mathrm{JH}$ in the neurobehavioral tests and $T \mathrm{TC}$ staining. $\mathrm{JH}$ performed the statistical analysis work and drafted the manuscript and DMD helped with editing and revising the paper. All authors read and approved the final manuscript.

\section{Funding}

This article is supported by a grant from the American Heart Association (17GRNT33670031) to Jiping Tang and a grant from the Natural Science Foundation Project of CQ CSTC (cstc2016jcyjA0172) to Juan Huang.

Availability of data and materials

The data used in this study are available from the corresponding author on reasonable request.

Ethics approval and consent to participate

All experiments performed in this study were in compliance with the National Institutes of Health guidelines for the handling of laboratory animals and approved by Loma Linda University Institutional Animal Care and Use Committee.

Consent for publication

Not applicable.

\section{Competing interests}

None of the authors have any conflicts of interests related to this work

\section{Author details}

${ }^{1}$ Institute of Neuroscience, Chongqing Medical University, Chongqing 400016, China. ${ }^{2}$ Department of Physiology and Pharmacology, Loma Linda University, Risley Hall, 11041 Campus St, Loma Linda, CA 92350, USA. ${ }^{3}$ Department of Neurology, Guizhou Provincial People's Hospital, Guiyang 550002, China. ${ }^{4}$ Department of Anesthesiology, Loma Linda University, Loma Linda, CA 92350, USA. ${ }^{5}$ Department of Neurosurgery, Loma Linda University, Loma Linda, CA 92350, USA.

Received: 27 January 2020 Accepted: 31 March 2020

Published online: 06 May 2020

\section{References}

1. Schreglmann M, Ground A, Vollmer B, Johnson MJ. Systematic review: longterm cognitive and behavioural outcomes of neonatal hypoxic-ischaemic encephalopathy in children without cerebral palsy. Acta Paediatr (Oslo, Norway : 1992). 2019:109 (1), 20-30. https://doi.org/10.1111/apa.14821.

2. Zhang Y, Xu N, Ding Y, Doycheva DM, Zhang Y, Li Q, Flores J, Haghighiabyaneh $\mathrm{M}$, Tang J, Zhang JH. Chemerin reverses neurological impairments and ameliorates neuronal apoptosis through ChemR23/ 
CAMKK2/AMPK pathway in neonatal hypoxic-ischemic encephalopathy. Cell Death Dis. 2019:10:97.

3. Dixon BJ, Reis C, Ho WM, Tang J, Zhang JH. Neuroprotective strategies after neonatal hypoxic ischemic encephalopathy. Int J Mol Sci. 2015;16:22368401.

4. Carloni S, Albertini MC, Galluzzi L, Buonocore G, Proietti F, Balduini W. Increased autophagy reduces endoplasmic reticulum stress after neonatal hypoxia-ischemia: role of protein synthesis and autophagic pathways. Exp Neurol. 2014;255:103-12.

5. Chen D, Dixon BJ, Doycheva DM, Li B, Zhang Y, Hu Q, He Y, Guo Z, Nowrangi D, Flores J, et al. IRE1 alpha inhibition decreased TXNIP/NLRP3 inflammasome activation through miR-17-5p after neonatal hypoxicischemic brain injury in rats. J Neuroinflammation. 2018;15:32.

6. Tu L, Wang Y, Chen D, Xiang P, Shen J, Li Y, Wang S. Protective effects of notoginsenoside R1 via regulation of the PI3K-Akt-mTOR/JNK pathway in neonatal cerebral hypoxic-ischemic brain injury. Neurochem Res. 2018;43: $1210-26$.

7. Bai X, Liu S, Yuan L, Xie Y, Li T, Wang L, Wang X, Zhang T, Qin S, Song G, et al. Hydrogen-rich saline mediates neuroprotection through the regulation of endoplasmic reticulum stress and autophagy under hypoxiaischemia neonatal brain injury in mice. Brain Res. 2016;1646:410-7.

8. Bhardwaj M, Leli NM, Koumenis C, Amaravadi RK. Regulation of autophagy by canonical and non-canonical ER stress responses. Seminars in cancer biology. 2019:51044-1579X(1019)30394-30393.

9. Martinez A, Lopez N, Gonzalez C, Hetz C. Targeting of the unfolded protein response (UPR) as therapy for Parkinson's disease. Biol Cell. 2019;111:161-8.

10. Han YK, Park G-Y, Bae MJ, Kim JS, Jo WS, Lee CG. Hypoxia induces immunogenic cell death of cancer cells by enhancing the exposure of cell surface calreticulin in an endoplasmic reticulum stress-dependent manner. Oncol Lett. 2019;18:6269-74.

11. Li X, Han F, Shi Y. IRE1a-XBP1 pathway is activated upon induction of single-prolonged stress in rat neurons of the medial prefrontal cortex. Journal of molecular neuroscience : MN. 2015;57:63-72.

12. Adams CJ, Kopp MC, Larburu N, Nowak PR, Ali MMU. Structure and molecular mechanism of ER stress signaling by the unfolded protein response signal activator IRE1. Front Mol Biosci. 2019;6:11.

13. Upton J-P, Wang L, Han D, Wang ES, Huskey NE, Lim L, Truitt M, McManus MT, Ruggero D, Goga A, et al. IRE1 a cleaves select microRNAs during ER stress to derepress translation of proapoptotic Caspase-2. Science (New York, NY). 2012, 338:818-822.

14. Tapeh BEG, Alivand MR, Solali S. The role of microRNAs in acute lymphoblastic leukaemia: from biology to applications. Cell biochemistry and function. 2019:10.1002/cbf.3466.

15. Omidkhoda N, Wallace Hayes A, Reiter RJ, Karimi G. The role of MicroRNAs on endoplasmic reticulum stress in myocardial ischemia and cardiac hypertrophy. Pharmacol Res. 2019;150:-104516.

16. van Kralingen JC, McFall A, Ord ENJ, Coyle TF, Bissett M, McClure JD, McCabe C, Macrae IM, Dawson J, Work LM. Altered extracellular vesicle microRNA expression in ischemic stroke and small vessel disease. Transl Stroke Res. 2019;10:495-508.

17. Burek M, König A, Lang M, Fiedler J, Oerter S, Roewer N, Bohnert M, Thal SC, Blecharz-Lang KG, Woitzik J, et al. Hypoxia-induced microRNA-212/132 alter blood-brain barrier integrity through inhibition of tight junction-associated proteins in human and mouse brain microvascular endothelial cells. Transl Stroke Res. 2019;10:672-83.

18. Moon GJ, Sung JH, Kim DH, Kim EH, Cho YH, Son JP, Cha JM, Bang OY Application of mesenchymal stem cell-derived extracellular vesicles for stroke: biodistribution and microRNA study. Transl Stroke Res. 2019;10: 509-21.

19. Fricker M, Tolkovsky AM, Borutaite V, Coleman M, Brown GC. Neuronal cell death. Physiol Rev. 2018;98:813-80,

20. Fann DY-W, Lee SY, Manzanero S, Tang SC, Gelderblom M, Chunduri P, Bernreuther C, Glatzel M, Cheng YL, Thundyil J, et al. Intravenous immunoglobulin suppresses NLRP1 and NLRP3 inflammasome-mediated neuronal death in ischemic stroke. Cell Death Dis. 2013;4:e790.

21. Platnich JM, Muruve DA. NOD-like receptors and inflammasomes: a review of their canonical and non-canonical signaling pathways. Arch Biochem Biophys. 2019;670:4-14.

22. Walsh JG, Muruve DA, Power C. Inflammasomes in the CNS. Nat Rev Neurosci. 2014;15:84-97.
23. Kahlenberg JM, Kang I. The clinicopathologic significance of inflammasome activation in autoimmune diseases. Arthritis \& rheumatology (Hoboken, NJ). 2019:10.1002/art.41127.

24. Yuan Y-Y, Xie K-X, Wang S-L, Yuan L-W. Inflammatory caspase-related pyroptosis: mechanism, regulation and therapeutic potential for inflammatory bowel disease. Gastroenterology report. 2018;6:167-76.

25. Fann DY-W, Lim Y-A, Cheng Y-L, Lok K-Z, Chunduri P, Baik S-H, Drummond GR, Dheen ST, Sobey CG, Jo D-G, et al. Evidence that NF-KB and MAPK signaling promotes NLRP inflammasome activation in neurons following ischemic stroke. Mol Neurobiol. 2018:55:1082-96.

26. Awad F, Assrawi E, Louvrier C, Jumeau C, Giurgea I, Amselem S, Karabina SA. Photoaging and skin cancer: is the inflammasome the missing link? Mech Ageing Dev. 2018;172:131-7.

27. Pedraza-Alva G, Pérez-Martínez L, Valdez-Hernández L, Meza-Sosa KF, AndoKuri M. Negative regulation of the inflammasome: keeping inflammation under control. Immunol Rev. 2015;265:231-57.

28. Glinsky GV. SNP-guided microRNA maps (MirMaps) of 16 common human disorders identify a clinically accessible therapy reversing transcriptional aberrations of nuclear import and inflammasome pathways. Cell cycle (Georgetown, Tex). 2008, 7:3564-3576.

29. Rice JE 3rd, Vannucci RC, Brierley JB. The influence of immaturity on hypoxic-ischemic brain damage in the rat. Ann Neurol. 1981;9:131-41.

30. Huang J, Liu W, Doycheva DM, Gamdzyk M, Lu W, Tang J, Zhang JH. Ghrelin attenuates oxidative stress and neuronal apoptosis via GHSR-1 a/AMPK/Sirt1/ PGC-1a/UCP2 pathway in a rat model of neonatal HIE. Free Radic Biol Med. 2019;141:322-37.

31. Zhang $C$, Jiang $M$, Wang W-Q, Zhao S-J, Yin Y-X, Mi Q-J, Yang M-F, Song YQ, Sun B-L, Zhang Z-Y. Selective mGluR1 negative allosteric modulator reduces blood-brain barrier permeability and cerebral edema after experimental subarachnoid hemorrhage. Translational stroke research. 2019: 10.1007/s12975-12019-00758-z.

32. Ma Q, Dasgupta C, Li Y, Bajwa MN, Xiong F, Harding B, Hartman R, Zhang L. Inhibition of microRNA-210 provides neuroprotection in hypoxic-ischemic brain injury in neonatal rats. Neurobiol Dis. 2016;89:202-12.

33. Matei N, Camara J, McBride D, Camara R, Xu N, Tang J, Zhang HJ. Intranasal wnt3a attenuates neuronal apoptosis through Frz1/PIWIL1a/FOXM1 pathway in MCAO rats. J Neurosci. 2018;38(30):6787-801.

34. Henshall CD. MicroRNAs in the pathophysiology and treatment of status epilepticus. Front Mol Neurosci. 2013;6(37):1-11.

35. Elmen J, Lindow $M$, Schutz $S$, Lawrence $M$, Petri A, Obad S, Lindholm M, Hedtjärn M, Hansen FH, Berger U, Gullans S, Kearney P, Sarnow P, Straarup EM, Kauppinen S. LNA-mediated microRNA silencing in non-human primates. Nature. 2008;452:896-9.

36. Jimenez-Mateos EM, Engel T, Merino-Serrais P, Mckiernan RC, Tanaka K, Mouri G, Sano T, O'Tuathaigh C, Waddington JL, Prenter S, Delanty N, Farrell MA, O'Brien DF, Conroy RM, Stallings RL, DeFelipe J, Henshallet DC. Silencing microRNA-134 produces neuroprotective and prolonged seizuresuppressive effects. Nat Med. 2012;18:1087-94.

37. Zhang Y, Zhang $X$, Wei Q, Leng S, Li C, Han B, Bai Y, Zhang H, Yao H. Activation of sigma-1 receptor enhanced pericyte survival via the interplay between apoptosis and autophagy: implications for blood-brain barrier integrity in stroke. Translational stroke research. 2019:10.1007/s12975-1201900711-12970.

38. Norton WT, Aquino DA, Hozumi I, Chiu FC, Brosnan CF. Quantitative aspects of reactive gliosis: a review. Neurochem Res. 1992;17:877-85.

39. Huang J, Lu WT, Sun SQ, Yang ZB, Huang SQ, Gan SW, Xu J, Qiu GP, Zhuo F, Zhu SJ, et al. Upregulation and lysosomal degradation of AQP4 in rat brains with bacterial meningitis. Neurosci Lett. 2014;566:156-61.

40. Northington FJ, Chavez-Valdez R, Martin LJ. Neuronal cell death in neonatal hypoxia-ischemia. Ann Neurol. 2011;69:743-58.

41. Lv Y, Sun B, Lu X-X, Liu Y-L, Li M, Xu L-X, Feng C-X, Ding X, Feng X. The role of microglia mediated pyroptosis in neonatal hypoxic-ischemic brain damage. Biochemical and biophysical research communications. 2019 S0006-0291X(0019)32123-32120.

42. Xu N, Zhang Y, Doycheva DM, Ding Y, Zhang Y, Tang J, Guo H, Zhang JH. Adiponectin attenuates neuronal apoptosis induced by hypoxia-ischemia via the activation of AdipoR1/APPL1/LKB1/AMPK pathway in neonatal rats. Neuropharmacology. 2018:133:415-28.

43. Ginet V, Pittet MP, Rummel C, Osterheld MC, Meuli R, Clarke PGH, Puyal J, Truttmann AC. Dying neurons in thalamus of asphyxiated term newborns and rats are autophagic. Ann Neurol. 2014;76:695-711. 
44. Serdar M, Kempe K, Rizazad M, Herz J, Bendix I, Felderhoff-Müser U, Sabir H. Early pro-inflammatory microglia activation after inflammation-sensitized hypoxic-ischemic brain injury in neonatal rats. Front Cell Neurosci. 2019;13: 237.

45. Yang $X-L$, Wang $X$, Shao L, Jiang G-T, Min J-W, Mei X-Y, He X-H, Liu W$H$, Huang $W-X$, Peng B-W. TRPV1 mediates astrocyte activation and interleukin-1 $\beta$ release induced by hypoxic ischemia $(\mathrm{HI})$. J Neuroinflammation. 2019;16:114.

46. de Rivero Vaccari JP, Lotocki G, Alonso OF, Bramlett HM, Dietrich WD, Keane RW. Therapeutic neutralization of the NLRP1 inflammasome reduces the innate immune response and improves histopathology after traumatic brain injury. Journal of cerebral blood flow and metabolism : official journal of the International Society of Cerebral Blood Flow and Metabolism. 2009;29:1251-61.

47. Zhao W, Han F, Shi Y. IRE1a pathway of endoplasmic reticulum stress induces neuronal apoptosis in the locus coeruleus of rats under single prolonged stress. Prog Neuro-Psychopharmacol Biol Psychiatry. 2016;69: $11-8$

48. Chavez-Valdez R, Flock DL, Martin L, Northington FJ. Endoplasmic reticulum pathology and stress response in neurons precede programmed necrosis after neonatal hypoxia-ischemia. International journal of developmental neuroscience : the official journal of the International Society for Developmental Neuroscience. 2016;48:58-70.

49. Schröder M, Kaufman RJ. The mammalian unfolded protein response. Annu Rev Biochem. 2005;74:739-89.

50. Huang S, Xing Y, Liu Y. Emerging roles for the ER stress sensor IRE1a in metabolic regulation and disease. J Biol Chem. 2019;294:18726-41.

51. Sidrauski C, Walter $P$. The transmembrane kinase Ire1p is a site-specific endonuclease that initiates mRNA splicing in the unfolded protein response. Cell. 1997:90:1031-9.

52. Feldman HC, Tong M, Wang L, Meza-Acevedo R, Gobillot TA, Lebedev I, Gliedt MJ, Hari SB, Mitra AK, Backes BJ, et al. Structural and functional analysis of the allosteric inhibition of IRE1 a with ATP-competitive ligands. ACS Chem Biol. 2016;11:2195-205.

53. Ghosh R, Wang L, Wang ES, Perera BGK, Igbaria A, Morita S, Prado K, Thamsen M, Caswell D, Macias $H$, et al. Allosteric inhibition of the IRE1a RNase preserves cell viability and function during endoplasmic reticulum stress. Cell. 2014;158:534-48.

54. Welihinda AA, Kaufman RJ. The unfolded protein response pathway in Saccharomyces cerevisiae. Oligomerization and trans-phosphorylation of Ire1p (Ern1p) are required for kinase activation. J Biol Chem. 1996;271: 18181-7.

55. Shamu CE, Walter P. Oligomerization and phosphorylation of the Ire1p kinase during intracellular signaling from the endoplasmic reticulum to the nucleus. EMBO J. 1996;15:3028-39.

56. Hetz C, Papa FR. The unfolded protein response and cell fate control. Mol Cell. 2018;69:169-81.

57. Iurlaro R, Muñoz-Pinedo C. Cell death induced by endoplasmic reticulum stress. FEBS J. 2016;283:2640-52.

58. Acosta-Alvear D, Zhou Y, Blais A, Tsikitis M, Lents NH, Arias C, Lennon CJ, Kluger Y, Dynlacht BD. XBP1 controls diverse cell type- and conditionspecific transcriptional regulatory networks. Mol Cell. 2007;27:53-66.

59. Walter $P$, Ron $D$. The unfolded protein response: from stress pathway to homeostatic regulation. Science (New York, NY) 2011, 334:1081-1086.

60. Oyadomari S, Mori M. Roles of CHOP/GADD153 in endoplasmic reticulum stress. Cell Death Differ. 2004;11:381-9.

61. Sokka A-L, Putkonen N, Mudo G, Pryazhnikov E, Reijonen S, Khiroug L, Belluardo N, Lindholm D, Korhonen L. Endoplasmic reticulum stress inhibition protects against excitotoxic neuronal injury in the rat brain. J Neurosci. 2007;27:901-8.

62. Dandekar A, Mendez R, Zhang K. Cross talk between ER stress, oxidative stress, and inflammation in health and disease. Methods Mol Biol (Clifton, NJ). 2015, 1292:205-214.

63. Shi S, Tan P, Yan B, Gao R, Zhao J, Wang J, Guo J, Li N, Ma Z. ER stress and autophagy are involved in the apoptosis induced by cisplatin in human lung cancer cells. Oncol Rep. 2016;35:2606-14.

64. Fan Y, Simmen T. Mechanistic connections between endoplasmic reticulum (ER) redox control and mitochondrial metabolism. Cells. 2019;8:1071.

65. Creeley CE, Dikranian KT, Dissen GA, Back SA, Olney JW, Brambrink AM. Isoflurane-induced apoptosis of neurons and oligodendrocytes in the fetal rhesus macaque brain. Anesthesiology. 2014;120:626-38.
66. Kesavardhana S, Kanneganti T-D. Mechanisms governing inflammasome activation, assembly and pyroptosis induction. Int Immunol. 2017;29:201-10.

67. Koyama K, Kangawa A, Fukumoto N, Watanabe K-I, Horiuchi N, Ozawa T, Inokuma H, Kobayashi Y. Histopathological study of encephalomalacia in neonatal calves and application of neuronal and axonal degeneration marker. J Vet Med Sci. 2018;80:1116-24.

68. Wei X, Yang Z, Liu H, Tang T, Jiang P, Li X, Liu X. MicroRNA-125a-3p overexpression promotes liver regeneration through targeting proline-rich acidic protein 1. Annals of hepatology. 2019:S1665-2681(1619)32229-X.

69. Yang M, Tang X, Wang Z, Wu X, Tang D, Wang D. miR-125 inhibits colorectal cancer proliferation and invasion by targeting TAZ. Biosci Rep. 2019;39:BSR20190193.

70. Sun L, Lian JX, Meng S. MiR-125a-5p promotes osteoclastogenesis by targeting TNFRSF1B. Cell Mol Biol Lett. 2019;24:23.

71. Hou P, Li H, Yong H, Chen F, Chu S, Zheng J, Bai J. PinX1 represses renal cancer angiogenesis via the mir-125a-3p/NEGF signaling pathway. Angiogenesis. 2019;22:507-19.

\section{Publisher's Note}

Springer Nature remains neutral with regard to jurisdictional claims in published maps and institutional affiliations.
Ready to submit your research? Choose BMC and benefit from:

- fast, convenient online submission

- thorough peer review by experienced researchers in your field

- rapid publication on acceptance

- support for research data, including large and complex data types

- gold Open Access which fosters wider collaboration and increased citations

- maximum visibility for your research: over $100 \mathrm{M}$ website views per year

At BMC, research is always in progress.

Learn more biomedcentral.com/submissions 